\title{
Restrictive Factors and Countermeasures of Economic Development Mode Transformation of Guangxi Coal Industry
}

\author{
Feng ZHAO \\ Guangxi University of Finance \& Economics, Nanning, China
}

\begin{abstract}
Coal is the basis and main energy in China, and its inefficient development and utilization led to serious ecological damage, for the reason that the economic development mode transformation of coal industry is imperative. This paper discusses the necessity, restrictive factors and countermeasures of economic development mode transformation of Guangxi coal industry, and makes useful exploration for sustainable development of the resource-based industries.
\end{abstract}

KEYWORD: Coal industry; Economic development mode transformation; Restrictive factor; Countermeasure

\section{INTRODUCTION}

The extensive economic development mode characterized with high energy consumption and high pollution has failed to maintain sustainable development due to the increasingly heavy resourceenvironmental pressure. And the resource-abundant regions, especially underdeveloped resourceabundant regions in China are universally confronted with the serious consequences of extensively exploiting resources. Coal is the basic and major energy in China and its consumption amount accounts for $70 \%$ of the total consumption amount of primary energy[1]. The sustainable development of coal industry in China plays a strategically decisive role in ensuring national energy security and the sound development of national economy. Since Guangxi in the south China has abundant coal resources and its coal industry takes up a large proportion in the industrial economy, it is of strategic and practical significance in the economic development mode transformation of the whole province through transforming the development mode of the coal industry.

\section{THE NECESSITY OF ECONOMIC DEVELOPMENT MODE TRANSFORMATION OF GUANGXI COAL INDUSTRY}

\subsection{Development status and main problems}

Guangxi lies in the southeastern edge of YunnanGuizhou Plateau. Special, complex geological structural movements result in its significantly different formation from other regions, which in turn leads to the formation of rich coal resources. Currently, the coal-bearing area in this province reaches 20,300 square kilometers, accounting for $5.8 \%$ of the total area; among its 109 county-level administrative regions, coal seams are found in 74; the total coal resources proved are 2.388 billion tons and the retainable reserves amount to 18.568 trillion tons. Promoted by the strategy of Grand Western Development in China and the rapid development of Beibu Gulf Economic Zone, Guangxi has witnessed prosperous industrial development in recent years. Meanwhile, the stable supply of energy and the sustainable development of the energy industry has been one of the most concerned issues in Guangxi. However, the extensive development mode of the coal industry and numerous problems in rational exploitation and comprehensive utilization of coal resources are unfavorable to the coordinated and sustainable development of the coal industry.

(1) Coal resources with less exploitation and utilization. Most existing coal mines in Guangxi were established from the 1970 to 1980 s and have developed to the middle and late periods of the service life. Besides, owing to Guangxi lies in a typical karst landform, the recovery rate of coal mining merely ranges from $15 \%$ to $25 \%$, far behind $30 \%$ which is the national average level.

(2) Irrational industrial structure. The structure of the coal industry in Guangxi is characterized by coal mines with an excessive number, a small average scale and low level of industrial concentration. In addition, the heavy industry, which is mainly composed of coal mining and raw material industries, 
occupies a large proportion. However, there is only a small proportion of coal processing and manufacturing industry. Besides, coal products are characterized by short processing chain, low processing degree and end consumer goods with a small proportion.

(3) Severely damaged ecological environment. Numerous middle and small-sized coal mines with insufficient capital often in situ cut trees to line tunnels. Thus, a great number of trees surrounding coal mines have been chopped down and ecological environment has been severely damaged. Additionally, coal mining, which exerts significant influences on water and land resources, results in the frequent occurrence of the natural disasters of surface subsidence, mountain landslide and debris flow.

\subsection{Necessity of economic development mode transformation}

The benign development of economy in a nation or region relies on its energy supply capability and supply-demand conditions. From the perspective of national economic development, energy supply presents an input-output relationship with GDP, with a correlation coefficient of 0.9341[2]. Therefore, energy production and supply greatly restricts the economic development and its mode transformation in China. As to Guangxi province, the coal industry is its basic industry. Statistics show that raw coal accounts for $60 \%$ in the production structure of primary energy in the province. The proportion of raw coal in energy consumption structure also exceeds $50 \%$. Therefore, coal plays an irreplaceable role in the rapid economic and social development in Guangxi. Owing to coal industry demonstrates a high correlation degree and covers wide fields, transforming the economic development mode of this industry is conducive to promoting the sustainable development of the following industries: power, metallurgy, building materials, chemistry, etc.

During recent years, facilitated by the deepened development and construction of Beibu Gulf Economic Zone and the Greater Mekong Sub-region economic cooperation, Guangxi has achieved rapid economic and social development. Thus, it has increasing demands for energy. With the advent of the 21st century, the gap of coal demand has increased annually. For example, 27.269 million tons of coal was imported to this province in 2011, occupying $15 \%$ of the total imported coal that year in China. Thus, energetically promoting the economic development mode transformation of coal industry can improve the output of this industry and ensure the supply of coal resources.

\section{RESTRICTIVE FACTORS OF ECONOMIC DEVELOPMENT MODE TRANSFORMATION OF GUANGXI COAL INDUSTRY}

\subsection{Restrict of property right structure}

The establishment of a modern property right system with clear rights and responsibilities and smooth operation is the foundation of the existence and development of the socialist market economy. According to the law in China, coal resources are owned by the state while enterprises can achieve coal mining rights by paying low commission. Moreover, these enterprises need to pay certain use and compensation fees of resources according to coal output. Such regulations of property right enable the original state-owned coal to become public resources characterized by competitiveness and non-exclusiveness. Currently, a modern property right system has not been constructed in the Guangxi coal industry and the shortfalls of the traditional property right system are still existent. Therefore, the inefficient structure adjustment and innovative technological capability, low operation efficiency of coal enterprises and unavoidable consequences generated by resource exploitation enable the coal industry to fail to satisfy the requirements of economic development mode transformation.

\subsection{Restrict of resource factors}

According to western economics theory, the foundation of industrial development is the input of resource elements. Generally speaking, resource elements include material and human resources, capital, etc. The quantity, quality, and allocation efficiency of the three supply elements basically decides the development mode and level of coal industry. The restriction of elements is firstly represented by inadequate capital. The transformation of economic development mode is associated with reform and opening up as well as the overall modernization construction of socialism. Due to the long process and difficulties of the above two projects, a considerable amount of capital is needed to support the transformation of economic development mode. Though Guangxi government has allocated special fund to support the transformation, coal enterprises merely obtain a small sum of capital owing to the number of smalland medium-sized coal enterprises in the province. Besides, because of few financing channels, the raised capital of these enterprises is limited. Furthermore, the lack of professional personnel is also an important factor limiting transformation mode. The professional personnel with undergraduate diploma in the coal system in the province merely occupy $3.1 \%$ of the staff. And few heads in work area received formal diploma education. 


\subsection{Lack of innovative capability}

Due to the lack of independent innovation awareness and inadequate capital, most coal enterprises only invest less than $1 \%$ of sales revenue in research and development, lower than 5\% which is the internationally acknowledged lowest level. Besides, the research and development center has not been established in many coal enterprises. Additionally, the cooperation mechanisms of such enterprises with universities and scientific research institutions, the incentive mechanism of technological innovation and the mechanism of transforming scientific and technological achievements are expected to be improved. Therefore, scientific research activities are not coupled with industrial development and scientific research achievements are disconnected with market demands. Insufficient system integrated innovative capability results in unsatisfactory results in learning and digest of foreign advanced technologies. Restricted by inadequate capital and technological capability, many coal enterprises are unwilling or have no ability to undertake technological innovation activities while they seek quick success and instant benefits and maximize immediate interests.

\subsection{Inadequate of policy support}

The transformation of the economic development mode in coal industry is considered to be a system engineering which involves fields, needs forceful policy support, and faces great reform difficulties. It needs the high coordination of governmental departments at all levels, including the Commissions of Development and Reform, Industry and Information Technology, State-owned Assets Supervision and Administration, and the Departments of Finance, Tax, Environmental protection, Human Resources, Social Security, etc. Besides, measures have to be formulated and carried out by these governmental departments. However, in the specific operation process, the related departments have not constructed communication and coordination mechanisms, policy supporting system, or relevant supporting measures for promoting the transformation of economic development mode in coal industry. These problems have greatly restricted the mode transformation in the industry.

\section{SUGGESTIONS AND COUNTERMEASURES FOR ACCELERATING ECONOMIC DEVELOPMENT MODE TRANSFORMATION}

\subsection{Strengthening policy support}

Firstly, formulating and implementing the structure adjustment policies of coal industry. Small-and medium-sized coal mines should be guided to undertake shareholding system transformation. Major coal mines should be supported to conduct merger and acquisition of small mines so as to implement scale production and intensive management. On this basis, the structure of coal industry can be more rational and the transformation of the economic development mode can be promoted. Secondly, to support coal enterprises to make innovations, finance and taxation policies should be established and carried out. Besides, the innovation incentive mechanism of coal technology and the mechanism of transforming scientific and technological achievements should be improved. Moreover, the finance and taxation policies which motivate coal enterprises to invest in research and development should be implemented. Furthermore, Guangxi should enhance the research and development of the technologies for alternative resources of coal. And the finance and taxation policies of supporting the popularization and application of energy-saving and environmental technologies should be carried out. Thirdly, rigid regulations on comprehensive utilization of resources and energy as well as environmental policies should be engineered. The supervising function of the government and the law enforcement dynamics for protecting environment should be strengthened to facilitate the transformation of the economic development mode of Guangxi coal industry[3].

\subsection{Developing circular economy}

Firstly, the relevant departments should firmly carry out the policies in energy industry in China, strengthen management of small coal enterprises with high pollution, and eliminate backward productivity, equipment and process. Besides, the production demonstration of clean coal should be conducted and preferential policies of encouraging coal enterprises to produce clean coal should be implemented. Secondly, coal enterprises in Guangxi should make great efforts to introduce new technologies and equipment according to the detailed indexes of energy-saving and emissionreducing and constantly promote the construction of green mines. Thirdly, Guangxi should actively develop pollution-free and high-tech industry and use high and new technology to transform the traditional industry. Additionally, the coal industry should be guided to follow a path of new-type industrialization with low consumption and pollution and maximum benefits.

\subsection{Facilitating coal technology innovation}

Firstly, the governments at all levels should earnestly increase investment in technological 
innovation of coal enterprises, create more financing channels for these enterprises and enhancing their vitality through capital allocation. Secondly, such enterprises should be guided to increase investment in establishment of technological research and development centers in various forms and to cooperate with universities and scientific research institutions in Guangxi. Thus, clean coal producing, energy-saving and environmental technologies can be developed and popularized. Thirdly, coal enterprises should be guided to perform technological innovation by taking market as guide, product as head, benefits as center and management as foundation. Fourthly, based on the reality of Guangxi, a scientific and rational appraisal system of technological innovation should be established. And the appraisal index of technological innovation of coal enterprises should be an important part in the appraisal category of the responsibility system of assets operation.

\subsection{Prolonging coal industry chain}

The prolonging process of the chain of coal industry is a process through which the coal industry gradually improves competitive advantages so as to realize sustainable development. The relevant departments should formulate rigid constraint policies as soon as possible and mandatorily facilitate the eco-transformation of coal and coal chemical industries. Firstly, the transformation of traditional industry should be quickened so as to form three industry chains: raw coal-clean coal-coal water slurry, power generation-power supplybuilding materials, and clean coal-coal liquefactionscoal chemical industry. Additionally, the processing depth of coal resource products is gradually improved, the industry chain is prolonged, and the added value of products is increased. Secondly, coal chemical industry and the fine processing industry of coal tar should be energetically developed. Besides, the synthesis technologies of dim ethyl oxalate, ethylene glycol, dim ethyl carbonate, etc[4]. by using coal base should be actively introduced and developed so as to form large-scale productivity as soon as possible.

\section{CONCLUSIONS}

Accelerating the economic development mode transformation of coal industry is a necessity of realizing the sustainable development of the economic and social development in China. And it also illuminates the idea of comprehensively implementing the scientific development concept in coal industry. According to the reality of the Guangxi coal industry, the transformation of the economic development mode in this industry is restricted by the factors of the unclear property right structure, inadequate resource, inadequate innovative capability and policy support. Therefore, this research proposed corresponding countermeasures of speeding up the economic development mode transformation in Guangxi coal industry. However, it has to be recognized that the mode transformation cannot be achieved overnight due to its long-term, complex and dynamic process. Thus, the development opportunities of the new round western development in China should be fully utilized. Besides, various favorable factors should be mobilized to accelerate the economic development mode transformation in Guangxi coal industry.

\section{ACKNOWLEDGEMENT}

National-sponsored Social Sciences Funding Program: Research on Industrial Transformation and Sustainable Development of Underdeveloped Resource-rich Area under the Perspective of Energyconservation and Emission-reduction (No. 12CJY003)

\section{REFERENCES}

[1] Hong, L. 2012. Thoughts and Suggestions on the Economic Development Mode Transformation of Coal Industry. Macroeconomic Management (5):65-67.

[2] Long, Z.P. 2007. Energy Consumption and GDP Growth. China Statistics (7):16-18.

[3] Po, Y.C. 2012. Exploration and Research on the Economic Development Mode Transformation of State-owned Coal Enterprises. Coal Economic Research (6):28-30.

[4] Quan, Y.Z. 2014. Research on the Economic Development Mode Transformation of Coal Enterprises. Knowledge Economy (11):10-12. 